\title{
Factors enhancing practitioners' motivation in small local constructor in Japan
}

\author{
Lingling Wang ${ }^{\mathrm{a}^{*}}$ and Tsunemi Watanabe \\ ${ }^{a}$ School of Economics and Management, Kochi University of Technology, 2-22 Eikokuji-cho, Kochi City, Kochi 780-8515, Japan \\ ${ }^{b}$ School of Economics and Management, Kochi University of Technology, 2-22 Eikokuji-cho, Kochi City, Kochi 780-8515, Japan
}

\begin{abstract}
In public construction procurement in Japan, the designated competitive bidding had been mainly used until the middle of 2000 s. This scheme has many advantages such as being able to select a reliable contractor with low transaction costs. It has a disadvantage, however, of possibility to cause collusive bidding particularly under shrinking construction investment period. To enhance transparency in procurement, the general competitive bidding has been introduced since the middle of 2000s. However, this reform seems to have been lower motivation of practitioners. Under the designated competitive bidding, many awarded vendors were able and willing to do good works as much as possible, some of which were not necessarily specified in contract documents. Price competition was not much severe, and good works were certainly led to award of the next project. Under the general competitive bidding, however, vendors are neither able nor willing to do works which are out of project scope. Price competition is now severer, and good works do not necessarily lead to award of the next project. Currently, thus, many practitioners now tend to do tasks as written in the contract document with demotivated feeling. To motivate construction practitioners, thus, becomes an urgent topic for the Japanese construction industry. This study conducted a field survey of practitioners' motivation in a successful small local constructor in Tokushima prefecture, Japan. This study identified several factors affecting motivation of local practitioners, including development and application of information and communication technology (ICT) well suited to the company and top management's attitudes to support employees. These factors enhance autonomy, competence, and relatedness of employees, which are three conditions for employees' intrinsic motivation. Employees' high motivation realized higher productivity and profit, which lead to high incentive. That is, there exists a cause and effect relationship between intrinsic motivation and incentive for company employees. The results hint a method of not only improving motivation of construction practitioners but also enhancing attractiveness of local construction industry in Japan.
\end{abstract}

(C) 2018 The Authors. Published by Diamond Congress Ltd., Budapest University of Technology and Economics Peer-review under responsibility of the scientific committee of the Creative Construction Conference 2018.

Keywords: motivation; ICT; local constructor; Japan ;

\section{Introduction}

In public construction procurement in Japan, the designated competitive bidding had been mainly used until the middle of 2000s. This scheme has many advantages such as being able to select a reliable contractor with low transaction costs. It has a disadvantage, however, of possibility to cause collusive bidding particularly under shrinking construction investment period. To enhance transparency in procurement, the general competitive bidding has been introduced since the middle of 2000s. However, this reform seems to have been lower motivation of practitioners. Under the designated competitive bidding, many awarded vendors were able and willing to do good works as much as possible, some of which were not necessarily specified in contract document. Price competition was not much severe, and good works were certainly led to award of the next project. Under the general competitive bidding, however, vendors are neither able nor willing to do works which are out of project scope. Price competition 
is now severer, and good works do not necessarily lead to award of the next project. Currently, thus, many practitioners now tend to do tasks as written in the contract document with demotivated feeling. To motivate construction practitioners, thus, becomes an urgent topic for the Japanese construction industry.

In this paper, the authors put the light on Otake Group Co., Ltd., referred as to "Otake group" hereafter, which is located in Mugi, Tokushima prefecture in Japan. The company realizes drastic improvement in business productivity and improvement of employee's work motivation by introducing ICT (Information and Communication Technology) actively in business.

Chapter 2 describes the history and management characteristics of the Otake group, and Chapter 3 introduces the features and effects of construction using the ICT of the company. Chapter 4 briefly reviews literatures on motivation research in the field of construction management. Chapter 5 gives summary and interpretations of interviews with employees. Chapter 6 states conclusions.

\section{History and management characteristics of the Otake group}

This chapter describes the company's history and management characteristics based on interviews with Mr. Kii (Senior Managing Director) and Mr. Yamanishi (Managing Director) conducted on September 27 and 28, 2017.

\subsection{History of Otake group}

The history of Otake group begins with establishment of Otake group privately owned by Mr. Tachi Otake in Mugi in May 1921. Because of the War and the South Sea Earthquake, Mugi suffered great damage. Otake group worked hard to regenerate the area through restoration works, town development activities, and countermeasure construction works against tsunami. In April 1951, Otake Group Co., Ltd. was established to make management transparent. After that, the group actively worked on the fishing port maintenance projects ordered by Tokushima Prefecture and started receiving road construction projects ordered by the Ministry of Construction in 1965. In 1987, the group became the top contractor in terms of the value of awarded contracts of projects ordered by Tokushima prefecture and hired approximately 150 employees.

As the number of port development projects decreases due to decline in fishing catch, however, the number and value of works completed mainly of port projects in prefecture decreased sharply. Followed by a drastic cut of public investment by the Democratic Party's administration, the value of works completed continued to decrease greatly, and the number of employees was reduced to approximately 25 people. The group made desperate efforts to rebuild management of receiving projects ordered by the national government and town office and cutting executive remuneration to zero. Under such circumstances, the Great East Japan Earthquake occurred. Demand for seismic reinforcement work for port increased, and value of works completed turned to increase. Then, before the MLIT (Ministry of Land, Infrastructure, and Transport) advocated "i-construction" to all over Japan, the group discovered, invested and utilized the "trump card" for utilizing ICT. As a result of that, the group is dramatically improving work productivity and enhancing work motivation of employees.

\subsection{Characteristics of management of Otake group}

The current characteristics of Otake group's managements are summarized as follows.

First, they are promoting further "in-house production," that is, strengthening the work force in the field. There are three reasons for this: (1) outsourcing is becoming more difficult because the number of subcontractors is decreasing, (2) each employee can work anywhere if she/he has her/his own skill, and (3) an employee can feel a sense of achievement by directly involved with field operation. The second is disclosure of financial statement of the group to all employees. Its purposes are to realize transparent management and to make employees interested not only in their own affairs but also in the management of the company. The third is to return a significant portion of profits to employees. The company's management policy is "Return profits to employees as fully as possible and not accumulate as president's private property."

In October 2016, the group was first certified as a construction company in Chugoku/Shikoku area based on the law concerning promotion of employment of youth, "Youth Ale certified company." In order for a company to be certified, it is necessary to meet twelve criteria. Among those criteria, it is extremely difficult for the small and medium-sized construction company to meet the criterion of "The average acquisition rate of the number of paid vacation days actually taken to the annual grant days of paid vacation for full-time employees is more than or equal 
to $70 \%$, or the number of paid vacation days actually taken by full-time employees is more than or equal to 10 days on average." It is noteworthy that the Otake group, which promotes in-house production, received this certification. It also hints that the group's management policy will be a reference to the future of local small and medium-sized construction companies.

\section{Characteristics of construction using Otake group's ICT Co., Ltd.}

Features and effects of construction using Otake group's ICT are organized as follows [1].

- Creation of hybrid 3D data by synthesizing LandXml (earthwork 3D) and TS-Xml (roadside structure 3D)

- Introduction of Construction Terminal, "Comfortable Measurement Navigation," developed by Construction Systems Co. Ltd. and LN-100 "Pile Navigation" developed by TOPCON Co., Ltd.

- Mount Hybrid 3D data on Comfortable Measurement Navigation

- Pile navigation of tracking the prism automatically through Wi-Fi communication

- Survey by only an inexperienced young employee

- Instruct the operator where and how deep she/he should excavate for foundation according to the cross section profile displayed on the tablet

- All manual calculations become unnecessary. The tablet instantly displays all necessary information with $3 \mathrm{D}$ data on route data.

- After completion of excavation for foundation, lay out of levelling using concrete, marking of formworks, and the height of the crown were measured by this young employee.

- Increase in work speed. Reduction of measurement cost to one-third of the conventional method

- Skilled engineers are freed from surveying work. As a result, they became able to conduct works at the office such as preparation of consultation documents with the client and quantity calculation, which used to be conducted after regular office hours.

- The problem of acquiring paid holidays by engineers, which was the most difficult, is being solved through work sharing with young employees.

Mr. Yamanishi said, "Now I am feeling effectiveness of reform of work life balance through using 3D data. V/C ("value to cost" inserted by the author) greatly increases by using 3D data. Creation and utilization technology of 3D design data will be a true technical power of the future civil engineering."

\section{Previous study in construction management field}

Mansfield \& Odeh (1991) examined factors that influence the motivation of construction project members [2]. Kim et al. (2015) investigated motivation factors that affect the productivity of construction workers in each country [3]. Kvorning \& Christensen (2015) clarified the process of small and medium construction company managers who are motivated to participate in the occupational health and safety program and participate. Cao et al. (2017) analyzed the factors that influence the motivation to introduce BIM into construction projects [4]. Furthermore, the index of PMBOK [5] has little motivation description, such as no motivation item. Overall, in the field of construction management, motivation research is still limited.

\section{Interviews with employees and their summary and interpretations}

On September 28, 2017, the authors conducted interviews towards 22 employees of Otake group regarding their motivations. The interviews were conducted dividing these employees into three groups: the first group mainly consisting of site workers, the second group mainly consisting of mid-level field management engineers, and the third group mainly consisting of young employees.

The followings are summary and interpretation of interview results.

First, some employees seem to have high intrinsic motivation, defined by Deci [6]. Particularly, young employees who conduct measurement tasks as if they play with smart phones have high intrinsic motivations. Mr. Kii and Mr. Yamanishi say, "They are never reluctant to do survey works. They hold tablets and do their works running, running, running, and running." These young employees seem to feel enjoyment of their works. Furthermore, three issues should be mentioned here. First, they do survey works alone. That is, they are given autonomy. Second, with the assistance of powerful hardware and software, their outputs were very accurate. As a result, they start feeling competence in survey works. Third, their relationship with their senior operators and engineers become better since 
those operators and engineers thank them for their accurate works and instructions. That is, they are feeling higher relatedness. Autonomy, competence, and relatedness are three components for intrinsic motivation. The young employees enjoy these three components.

Another player who seems to have intrinsic motivation is Mr. Yamanishi. His nick name is "IT geek." As represented with this nick name, he looks to enjoy very much when he operates and explain the software he developed. Needless to say, he enjoys autonomy and competence. As a result of his kind teaching to young employees, he is appreciated as like the "God" by them. He is feeling closer relatedness to young employees.

There are not a few criticisms against existence of intrinsic motivation at work place. Thus, our observation that young employees and management seems to have intrinsic motivation is valuable hypothesis which needs rigorous validation.

Second, high survey performance by young employees leads to higher productivity and profit. This becomes a foundation of incentive such as higher bonus and acquisition of paid holidays. This cause and effect relationship between intrinsic motivation and incentive should be noteworthy. For most management, the objective of ICT introduction is enhancement of productivity, quality, or safety. Otake group was not exceptional. It should be mentioned, however, that, in reality enhancement of intrinsic motivation of young employees was the first impact of ICT introduction and that incentive provision was its result.

Third, the management seems to practice the principle of risk management (ISO 31000), "the objective of risk management is creation and maintenance of value." Regarding investment in ICT, Mr. Yamanishi said, "I felt that these technologies can be used!" and proposed ICT investment to Mr. Kariya, the president. Mr. Kariya approved it. Because this was a big investment for small constructor, it may exacerbate the company's financial risk. This investment seemed a risky decision to the authors.

Two points should be mentioned here. The first point is that this large amount of ICT investment was made to create "value" of improving productivity of work. As a result of this investment, the company has created unexpected value of enhancing intrinsic motivation of young employees. The second point is that management did not perceive the financial risk associated with this investment. In other words, the financial risk associated with this investment was significantly reduced by management's ability: their technological capability and deep insight. Therefore, this big investment seems nothing more than practicing the risk management principle: risk management for creation and maintenance of value.

Fourth, motivation structure seems able to be represented with the upside down pyramid type cone floating on the water surface like the upside down iceberg (Figure 1). The upside down pyramid is often used to represent the idea that the higher level managers support lower level managers and employees. Here support by higher level managers is considered inclusion of motivating lower level employees. As already mentioned, young employees involved with survey works have high intrinsic motivation. Their high motivations and performance are paid attention by mass media. Their "visible" motivations are supported by senior employees' "invisible" motivations. Senior employees not only appreciate young employees' works but also check whether there is no mistake in the data acquired by young employees. This warm appreciation and strict checking by senior employees motivates young employees to do even more accurate works. The management at the bottom of the upside down iceberg does appropriate risk management to create and maintain value, which becomes a foundation for motivation of all employees.

Work motivation might be discussed using waterfowl. Even though waterfowl looks progressing elegantly on the water surface, she/he moves her/his legs very hard. It should be noted that a) invisible motivations of senior employees and management exist in addition to visible motivations of young employees, and b) the invisible motivations and visible motivations interact each other.

Fifth, the managements are motivated to educate and develop young employees. Sources of managements' motivation are not only their desire for company existence but also their feeling that they have been raised by the region. During the interview, Mr. Kii and Mr. Yamanishi kept repeating that they have been raised by the region so that they should and want to return to the region. Education and development of young employees contributes to not only stabilization of the company but also sustainable development of the region.

As described previously, Otake group had 150 employees at the peak time but only 25 people at the hardest time. Even the business of a constructor with such a long history is highly uncertain. The management seems to sincerely wish that employees can survive in other company even if they should leave the company. This wish seems a fundamental reason to motivate employees in Otake group. 


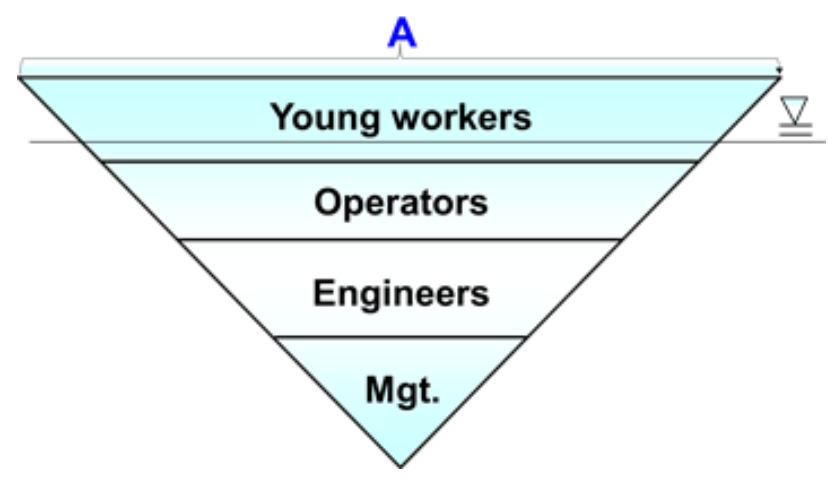

Fig. 1. Upside down iceberg.

\section{Conclusions}

To motivate construction practitioners, thus, becomes an urgent topic for the Japanese construction industry.

In this paper, the authors put the light on Otake Group Co., Ltd., referred as to "Otake group" hereafter, which is located in Mugi, Tokushima prefecture in Japan. The company realizes drastic improvement in business productivity and improvement of employee's work motivation by introducing ICT (Information and Communication Technology) actively in business.

First, some employees seem to have high intrinsic motivation, defined by Deci. They seem to enjoy autonomy, competence, and relatedness, which are three components for intrinsic motivation. There are not a few criticisms against existence of intrinsic motivation at work place. Thus, our observation that young employees and management seems to have intrinsic motivation is valuable hypothesis which needs rigorous validation.

Second, high survey performance by young employees leads to higher productivity and profit. This becomes a foundation of incentive such as higher bonus and acquisition of paid holidays. This cause and effect relationship between intrinsic motivation and incentive should be noteworthy.

Third, the management seems to practice the principle of risk management (ISO 31000), "the objective of risk management is creation and maintenance of value." The large amount of ICT investment was made to create "value" of improving productivity of work. The financial risk associated with this investment was significantly reduced by management's ability: their technological capability and deep insight.

Fourth, motivation structure seems able to be represented with the upside down pyramid type cone floating on the water surface like the upside down iceberg. Young employees' "visible" motivations are supported by senior employees" "invisible" motivations. Work motivation might be discussed using waterfowl. Even though waterfowl looks progressing elegantly on the water surface, she/he moves her/his legs very hard. It should be noted that a) invisible motivations of senior employees and management exist in addition to visible motivations of young employees, and b) the invisible motivations and visible motivations interact each other.

Fifth, the managements are motivated to educate and develop young employees. Sources of managements' motivation are not only their desire for company existence but also their feeling that they have been raised by the region. Education and development of young employees contributes to not only stabilization of the company but also sustainable development of the region. Even the business of a constructor with such a long history is highly uncertain. The management seems to sincerely wish that employees can survive in other company even if they should leave the company. This wish seems a fundamental reason to motivate employees in Otake group.

\section{Acknowledgements}

We would like to thank Mr. Otake Corporation and Mr. Kazutoshi Ishida, Regional Development Bureau of the Ministry of Land, Infrastructure and Transport, for their cooperation. This study was financially supported by Japan and Grant-in-Aid for Scientific Research (A) (Project No. 16H02356). 


\section{References}

[1] "How to Work by Effectively Utilizing Three-Dimensional Data" Otake Group Co., Ltd., JACIC Information No. 116, 2017.7

[2] N. R. Mansfield and N. S. Odeh, Issues affecting motivation on construction projects, Project Management. Vol. 9, No. 2 (1991) 93-98.

[3] S. Kim et al., Cultural differences in motivation factors influencing the management of foreign laborers in the Korean construction industry, International Journal of Project Management. 33 (2015) 1534-1547.

[4] D. Cao et al., Identifying and contextualising the motivations for BIM implementation in construction projects: An empirical study in China, International Journal of Project Management. 35 (2017) 658-669.

[5] PMI, A Guide to the PROJECT MANAGEMENT BODY OF KNOWLEDGE (PMBOK GUIDE), 5th Edition, 2013

[6] E. Deci and R. Frust: Why we do what we do, Penguin Books, 1987. 